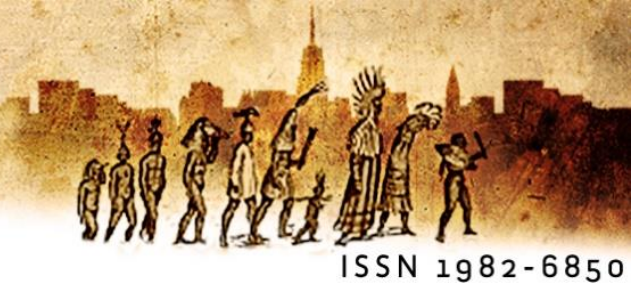

\title{
Gramática, estilo e ensino: uma perspectiva discursiva
}

\author{
Miriam Bauab Puzzo i (UNITAU)
}

\begin{abstract}
Resumo:
O objetivo deste artigo é discutir a questão da gramática em relação ao estilo como sugestão ao ensino de língua. A teoria dialógica da linguagem de Bakhtin e o Círculo no que concerne aos conceitos de língua, linguagem, gênero discursivo e estilo fundamenta a pesquisa e as análises. Para cumprir tal proposta foram selecionados alguns minicontos de Dalton Trevisan do livro 234 (1997) como objeto de análise. Como conclusão sugere-se a inclusão do estilo numa perspectiva discursiva, como recurso produtivo ao ensino de língua.
\end{abstract}

Palavras-chave: gramática; estilo; Ensino.

\section{Abstract:}

This article aims to discuss the question of grammar in relation to style as a suggestion to language teaching. The dialogical theory of Bakhtin's language and the Circle regarding the concepts of language, language, discursive genre and style ground research and analysis. In order to fulfill this proposal, some Dalton Trevisan little short stories of the book 234 (1997) are selected as the object of analysis. In conclusion, we suggest the inclusion of style in a discursive perspective as a productive resource to language teaching.

Keywords: grammar; style; teaching

O mundo contemporâneo apresenta uma gama complexa no que se refere às diversas formas de interação e comunicação humanas. A linguagem concebida como oralidade e escrita já não contempla a multiplicidade dos novos recursos que se apresentam ao homem em sociedade. Novas formas de interação à distância como as possibilidades oferecidas pela internet, pelos celulares e tablets ampliaram sobremaneira o desenvolvimento de novas linguagens.

Além disso, o espaço social diversificado pela integração de grupos sociais no contexto urbano tem modificado a compreensão da linguagem, antes reduzida à norma 
padrão como modelo. Novos conceitos decorrentes dessa integração social exigem um olhar diferenciado na forma de abordagem em sala de aula. A partir do conceito de letramento como um processo contínuo das práticas letradas, o de multiletramento procura incluir dois tipos específicos de multiplicidade presentes na sociedade atual urbana: multiplicidade cultural das populações e multiplicidade semiótica de constituição de textos dos mais variados campos de produção e circulação, como aponta Rojo (2012).

Os pesquisadores no âmbito do ensino entre eles Rojo e Moura (2012), Rojo (2013), Rojo e Barbosa (2015), Bunzen e Mendonça (2013) têm se debruçado sobre o tema do ensino discutindo a necessidade de inserção das novas formas de linguagem em sala de aula. Têm por objetivo desenvolver a capacidade de leitura e compreensão de textos no âmbito da multiplicidade cultural e suas diversas manifestações no contexto social contemporâneo. Conceitos como múltiplas linguagens e multiletramentos passaram a fazer parte do repertório atual de ensino de língua. Novas formas de instrumentos, além da escrita manual e impressa, tais como imagens em movimento, áudio, vídeos, mensagens via whatsapp, além de possibilidades de tratamento de textos com a possibilidade de edição e diagramação, influem na elaboração de múltiplos gêneros impressos, alterando seu estilo e rompendo regras instituídas.

Os hipertextos e as hipermídias também apresentam uma linguagem mais direta e fragmentada comum na comunicação informal. Todas essas formas de interação comunicativa numa estrutura linguística mais sintética e dinâmica atuam em enunciados escritos, principalmente os literários e os midiáticos. Portanto é preciso pensar em métodos de ensino que se tornem adequados a esse contexto, ampliando as práticas de leitura e interpretação de enunciados em sala de aula. Como refletem Kleiman, Ceniceros e Tinoco (2013, p.69), no que diz respeito à qualidade do ensino, "o arcabouço estrutural da escola do século XXI ainda se inspira no modelo de 'escola do século passado'".

Já no século $X X$, os estudos gramaticais exigiam novos métodos de ensino como demonstra Bakhtin (2013) em sua prática pedagógica na Rússia. Essa discussão se acentua no século XXI. Muitas das práticas aplicadas pelo professor Bakhtin ainda são inspiradoras para o ensino de língua numa proposta discursiva, escolhendo textos mais 
permeáveis à expressividade autoral, tais como os jornalísticos e os literários, para discussão da linguagem (PUZZO, 2012; 2013; 2014; 2019).

Assim, novos desafios se apresentam aos mestres para transpor os limites do ensino tradicional, exigindo formas de compreensão e de transmissão da linguagem nas várias esferas de produção e circulação com as quais se deparam os jovens na atualidade.

Some-se a isso o aumento do contingente de alunos no ensino público fundamental e médio os quais necessitam de métodos estratégicos para tornar esse ensino significativo.

Como consequência, não é mais possível tratar da estruturação gramatical da língua sem considerar o estilo do gênero e as inflexões individuais dos enunciadores que transcendem a norma gramatical. A linguagem expressiva nesses casos oscila entre norma e variação como postula Bakhtin (2013). Desse modo, o tratamento dado ao ensino da gramática normativa sofre deslocamentos em função do estilo genérico e individual nos mais variados gêneros discursivos. O grande desafio é tratar das normas em relação as suas variações presentes em enunciados autorais.

Os textos literários, além dos midiáticos e publicitários, oferecem um exemplo produtivo para essas discussões de confronto entre a norma e suas possibilidades expressivas.

Sob esse aspecto, a linguagem nos diversos gêneros sob a influência dos novos meios de comunicação no contexto contemporâneo, adapta-se ao ritmo de vida moderno, concretizando-se em uma linguagem mais enxuta. A predominância de frases curtas e períodos fragmentados distancia-se da escrita estruturada de acordo com a prosa que prima pelo emprego de termos coesivos e períodos mais extensos.

Nos gêneros da esfera literária encontram-se exemplos desse estilo transgressor de linguagem mais direta e breve. Os gêneros discursivos dessa esfera apresentam peculiaridades estilísticas pela maior liberdade que têm os autores para adequar a linguagem a propostas renovadoras, muitas vezes mesclando estilo de gêneros diferentes. Os minicontos, constituídos por núcleos narrativos breves, apresentam essa necessidade de acompanhar o ritmo da vida moderna.

É o caso das ministórias como as nomeia Dalton Trevisan, um conjunto de instantâneos da vida urbana que exige do leitor uma leitura interativa para compreender 
os diversos fragmentos. Por esse estilo transgressor, os fragmentos 33-34-35-36-222 e 223 da coletânea de Trevisan 234 (1997) foram selecionados para análise do estilo em relação à gramática da língua e seus efeitos de sentido.

Este artigo se organiza em tópicos. Primeiramente, discute-se o conceito de gênero discursivo e estilo e sua relação com os minicontos. A seguir a análise demonstrativa dos recursos estilísticos e seus efeitos de sentido em relação à norma gramatical. E por fim uma breve conclusão.

\section{Gênero, estilo e gramática}

O conceito de gênero numa perspectiva discursiva, como discutem Bakhtin e o Círculo no início do século $\mathrm{XX}$, propicia ainda hoje pesquisas que iluminam aspectos da linguagem comunicativa que se renovam a cada dia em função das transformações e das necessidades próprias do contexto social.

Nessa perspectiva teórica, os gêneros devem ser observados em seus elementos constitutivos em função da proposta do autor, do público leitor e do contexto de produção, como teoriza Bakhtin em Gêneros do discurso (2016). A forma estável com que se constituem, permitindo a sua apreensão e reprodução nas diversas instâncias sociais em que circulam, é relativa em função das transformações sociais e das necessidades dos enunciadores em relação ao público. Essa capacidade de atualização dos gêneros em função do desenvolvimento social e tecnológico justifica a dificuldade cada vez mais acentuada de caracterização genérica, principalmente no que tange às expectativas do público atual e das respostas de seus autores. Portanto, o estilo genérico sofre alteração tanto em função das transformações sociais quanto em função do estilo individual de seus enunciadores. Assim como os gêneros, a língua também acompanha esse movimento evolutivo do contexto social, numa perspectiva discursiva, como pontua Volochínov (2013 b, p.157):

A língua não é de modo algum um produto morto, petrificado, da vida social: ela se move continuamente e seu desenvolvimento segue aquele da vida social. Esse movimento progressivo da língua se realiza no processo de relação entre homem e homem, uma relação não só produtiva, mas também verbal. Na comunicação verbal, que é um dos aspectos do mais amplo intercâmbio comunicativo - o social -, elaboram- 
se os mais diversos tipos de enunciações, correspondentes aos mais diversos tipos de intercâmbio comunicativo social.

Em consonância com essa dinâmica transformadora da língua, como material constitutivo de toda forma de comunicação, os gêneros discursivos também sofrem alterações estilísticas genéricas e individuais. Dessa forma é possível observar as variações em torno da norma gramatical instituída, configurando a língua em sua natureza viva, como pontua Bakhtin (2013, p.23): "As formas gramaticais não podem ser estudadas sem que se leve sempre em conta seu significado estilístico. Quando isolada dos aspectos semânticos e estilísticos da língua, a gramática inevitavelmente degenera em escolasticismo."

Nessa vertente, o conceito de estilo e de estilística não se reduz à discussão da originalidade do autor como concebiam os românticos, ou apenas como desvios da norma. Na perspectiva discursiva, o estilo decorre da concepção dialógica intrínseca à linguagem, como resultado da relação eu/outro e não uma simples inspiração individual. As transformações e as pressões do contexto social atuam sobre o enunciador, cuja resposta é o enunciado concreto, que na concepção teórica do Círculo representa uma resposta autoral em relação ao meio social e ao leitor pressuposto (BAKHTIN, 2016) por meio do qual o autor se manifesta axiologicamente.

Ao tratar desse tema, Volochínov (2013 a, p.97) afirma que "o estilo é pelo menos dois homens, ou mais exatamente, é o homem e seu grupo social na pessoa de seu representante ativo - o ouvinte, que é o participante permanente do discurso interno e externo do homem."

É justamente essa relação com o público que refrata as peculiaridades genéricas na atualidade. A agitação da vida urbana e os recursos tecnológicos acessíveis à grande parte da população interferem no estilo do autor que tem em mente o horizonte social do leitor.

A produção de Trevisan exemplifica essa relação autor/contexto/ público leitor. Dedicado à produção de contos e novelas, o autor curitibano inicia sua carreira produzindo narrativas mais extensas, inovando na escolha dos temas extraídos do cotidiano, como se fossem reportagens da vida real. Suas primeiras obras, entre elas Novelas nada exemplares (1959), Cemitério de elefantes (1964), O vampiro de Curitiba 
(1965), entre outras, encontram-se nessa linha. Contudo, ao longo do tempo, o autor desenvolve uma linguagem mais sintética, com termos mais diretos, muitas vezes agressivos, sem preocupação com a estética na vertente romântica que prioriza o belo. $O$ estilo enxuto, sem retoques, redunda nos minicontos como os selecionados da coletânea 234 .

Em entrevista ao repórter do jornal online, Rascunho: O jornal de literatura do Brasil, Trevisan sinaliza indiretamente seu processo de elaboração, como um trabalho consciente de mobilização dos recursos de linguagem e de sua estruturação.

Não acordei numa bela manhã decidido a optar por um estilo assim ou assado. Frito ou cozido. Essas coisas não acontecem desse jeito. Outra bobagem é quando chamam meus novos contos de haicais. Cretinice. Disponivel em http://rascunho.rpc.com.br/ (acessadoem3o/og/2010)

Na fala do autor, apesar da ironia, observa-se a proposta de inovação como uma premência do tema, pois, como pontua em outro momento, suas personagens são extraídas do cotidiano, inspiradas em pessoas reais que encontra nas ruas de Curitiba:

\begin{abstract}
Você sabe, todos sabem: minhas figurinhas são de carne e osso. Existem de verdade. Estão lá fora, trabalhando, comendo, dormindo. Às vezes sou ameaçado, porque fulano e beltrano não gostaram de se ver num conto meu. Então, fico sem aparecer na praça duas, três semanas. Isso me preocupa. (Idem, ibidem)
\end{abstract}

A proposta de retratar personagens de carne e osso aproxima suas histórias das reportagens jornalísticas, inclusive na forma "quase objetiva" de retrato do real. O distanciamento mantido como artifício estilístico, com o uso da $3^{\text {a }}$ pessoa, cria a sensação de objetividade na composição do conto e de fragmentação e concisão estrutural da linguagem. Como consequência, o estilo genérico do conto sofre deslocamentos, assim como a língua se adapta à sua proposta comunicativa, inovando em sua estruturação sintática. Por essas características, suas ministórias, como gênero ficcional moderno, merecem ser discutidos com o intuito de ressaltar suas peculiaridades linguísticas que provocam múltiplos efeitos de sentido.

\title{
Miniconto, coesão e coerência
}

Nessa coletânea, os minicontos são organizados de modo diferenciado, indicados por números como o próprio título 234 indica. Eles se organizam de modo 
aparentemente aleatório: uns mais breves como se fossem um provérbio ou um axioma, sem personagens nem cenário, e outros mais longos, cujas referências ao contexto se limitam às ações executadas pelas personagens de modo funcional. A princípio parecem desconectados, mas a leitura sequencial pode sinalizar uma relação intrínseca entre eles. Os mais longos parecem relacionar-se com os mais breves, estabelecendo entre eles uma possível relação, como se fossem os fatos narrados servissem de comprovação daqueles breves comentários.

Portanto, as narrativas dessa coletânea evidenciam a ruptura com o estilo genérico desde o início, em sua forma de apresentação: os títulos são substituídos por números sequenciais, sem indicação das possíveis relações entre os diversos fragmentos. Alguns mais breves, aparentemente aleatórios, constituídos por períodos desconectados, rompem a sequência coesiva da linguagem em prosa. O estilo responsável pela brevidade e por termos da linguagem comum, selecionados de modo preciso, entra em sintonia com o tema da violência do ser humano que se manifesta nas relações sociais. As personagens são representadas pelos seus atos e as particularidades de cada uma estão reduzidas ao essencial para configurá-las em seu ambiente.

Para efeito demonstrativo, foram selecionados seis exemplares, destacando-se os recursos linguísticos e expressivos que deixam entrever a visão ético-estética do autor frente às condições sociais de seres humanos marginalizados.

O fragmento 33 (p.22), "A santidade do pai é alcançada pela danação do filho.", constituído de uma linha apenas, como um dito popular atribuído a uma voz desconhecida, grifado em itálico, parece algo solto desprovido de relação de sentido. $O$ leitor, tomado de surpresa, não entende imediatamente a que se refere. $O$ trecho parece uma citação ou um comentário verbalizado internamente como se fosse um monólogo.

Entretanto, na sequência imediata, o de número 34, possibilita estabelecer algum nexo entre eles. A cena inicial é um instantâneo flagrado por uma personagem em primeira pessoa. O sentimento de comoção, indicado pelos olhos marejados de um senhor, é compartilhado pela personagem que narra: "E, sem querer, também eu comovido" (p.22). Os comentários do narrador constituídos por frases interrogativas 
expressam o impacto produzido pela imagem do pai envelhecido: "Diante de mim o feroz tirano da família? Ditador da verdade, dono da palavra final?" (idem). O espanto do narrador diante da fragilidade de uma personagem familiar, reconhecida pelo seu autoritarismo, transfere-se para o leitor.

A relação de familiaridade entre ambos revela laços de proximidade que vão aos poucos se descortinando aos olhos do leitor ao se deparar com a revelação "Meu pai saca o relógio do colete, dois giros na corda." (idem) Nesse momento torna-se evidente a relação com a narrativa anterior. Parece que o pai idoso e adoentado muda de estatuto diante do filho, pois de tão frágil e doente parece atingir a santidade em oposição ao sofrimento humano a que o filho se acha condenado. O trecho "Presuroso, digo que se vá. Doente, não apanhe friagem. E ele sem escutar." (idem) demonstra a relação conflitante entre pai e filho, agressividade e afeição, constituído por frases breves sem elementos coesivos.

A narrativa vai se constituindo pelo discurso interior e por diálogos não marcados: indireto e direto sem nenhuma indicação: "Pressuroso, digo que se vá", pelo discurso indireto, demonstra a entonação afetiva do filho que a seguir se manifesta de modo direto como um pensamento verbalizado: "Doente, não apanhe friagem." 0 verbo no imperativo cria a ambiguidade do trecho, não é possível saber se foi pensado ou verbalizado oralmente como uma ordem dada ao pai. A ambiguidade é desfeita pela observação que vem a seguir: "E ele sem escutar". Ainda assim, essa frase conclusiva deixa em suspenso o motivo de o pai não escutar: talvez por ser surdo? Ou por fingir não ouvir a recomendação do filho? Por teimosia? O autor deixa a cargo do leitor a conclusão, pois nenhuma delas pode ser descartada.

O fragmento seguinte parece um registro deslocado de qualquer referência: "Três da manhã. As batidas do Juízo Final na tua porta ou o peixinho vermelho estala o bico lá no aquário?" (p.23). Novamente um fragmento em itálico, sem nenhuma relação aparente com os dois trechos anteriores. É uma pergunta, uma dúvida ou uma reflexão silenciosa? Não há indícios que permitam ao leitor entender esse fragmento. Não se sabe a quem o narrador se refere ao usar o pronome possessivo "tua", nem quando menciona dois termos tão distanciados no plano semântico "juízo final" e "peixinho vermelho". É um questionamento que se aproxima do nonsense. 
No fragmento 36 (p.23) que vem a seguir, os laços familiares se estabelecem novamente. Ele continua pela repetição do período final do fragmento 34: "E ele sem escutar". O narrador de novo mistura os discursos "Olha de novo o relógio. Aceno que pode ir, não espere a partida. Quero ver a hora?" (p.23). A descrição da ação e a manifestação do diálogo encontram-se imbricados, cabendo ao leitor estabelecer o sentido, refazendo a trama narrativa. A atitude do pai se mescla à atitude do filho, a preocupação com as horas tanto pode ser imputada ao pai como ao narrador em primeira pessoa. A relação com o tempo já aparece nos fragmentos anteriores, tanto como uma preocupação do pai, quanto do narrador quando associa as batidas do relógio "três da manhâ", com as batidas do "Juízo Final". A linguagem figurada, fazendo remissão ao episódio bíblico do Apocalipse, parece sinalizar o instante final, o julgamento após a morte. A que se refere, então, essa imagem? Alguns termos parecem sugerir o final de uma relação familiar: "Nosso último encontro"; "ainda na despedida"; "vidraça de silêncio a nos separar"; "Desta vez para sempre." A menção ao julgamento final e à separação definitiva parece articular os fragmentos de modo a possibilitar uma imagem derradeira estabelecida entre pai e filho. Nesse encontro, o filho reavalia sua relação com o pai autoritário que se fragiliza diante da velhice e da morte.

Sem explicitar o tipo de relacionamento entre eles, os atos sugerem uma relação familiar tensa e dolorosa entre o filho e seu pai, cujo encontro final coloca em cheque $o$ estereótipo construído pelo filho ao longo da vida. A amargura do conflito entre pai e filho se torna um ato de aproximação afetivo, minimizando os traumas e os desencontros vividos por ambos. Numa leitura retroativa do fragmento 33, é possível dar sentido ao que parecia aleatório: "A santidade do pai é alcançada pela danação do filho". De repente, o pai se torna um ser menos prepotente, mais humilde diante do final da sua existência, enquanto o filho se encontra condenado a continuar vivendo seu drama existencial: "danação do filho".

Os fragmentos 35 e 36, expressam o mesmo processo dos anteriores. O primeiro, assim como o 33, está reduzido a duas linhas, como se fosse um dito popular: "Três da manhã. As batidas do Juízo Final na tua porta ou o peixinho vermelho estala o 
bico lá no aquário?" A interrogação coloca em questionamento as relações de similaridade ou de oposição como a conjunção alternativa sugere.

Seria um mero acontecimento rotineiro como o aprisionamento de um peixe no aquário? Ou um momento definitivo, um julgamento final após a morte? Algumas indicações sugerem o adeus definitivo. Após algumas observações de ordem geral "ele sem escutar", "Olha de novo o relógio, Aceno que pode ir, não espere a partida". A seguir o relato torna-se mais dramático: "Nosso último encontro, sei lá. E, ainda na despedida, o eterno equívoco entre nós. Maldita vidraça a nos separar. Desta vez para sempre." (p. 23).

Esses dois fragmentos apresentam fatos que se relacionam com os dois anteriores. Não há indicação individual das personagens, elas são denominadas pela relação familiar, assim como os núcleos narrativos não apresentam um título que permita a identificação o tema narrativo. Este se constrói com a ajuda do leitor que procura encontrar algum sentido nos fatos relatados. O desencontro existencial e conflitante evidenciado nos dois fragmentos anteriores parece amenizar-se no instante da partida, como se fosse um momento solene e ao mesmo tempo dramático.

O fato é relatado como um episódio cotidiano, um relacionamento familiar conflitante entre pais e filhos, sugerindo o conflito entre duas gerações. Contudo, pela ausência de dados e pelas breves informações sobre a ação das personagens é possível situá-los num contexto de privação: o velho vai tomar o trem, não carrega bagagem e só tem o relógio como referência para marcar o tempo. A visão do pai já idoso e doente provoca o impacto na personagem que se surpreende diante da figura paterna envelhecida. Os conselhos ditados ao velho, cuja imagem de autoridade e prepotência é substituída pela fragilidade, afetam a antiga relação familiar. O filho, agora na posição de adulto saudável, é ignorado pelo senhor que não escuta seus conselhos. A inversão de papéis fica evidente e justifica os ditos em itálico 33 e 35, anteriores aos dois fragmentos narrativos: 34 e 36 . Essa relação de sentido só aos poucos pode ser articulada entre os trechos como um desafio ao leitor.

Nos últimos trechos selecionados, 222 e 223, a ordem aparece invertida, o comentário breve de duas linhas apenas aparece depois do relato narrativo. Enquanto os primeiros referem-se à separação, um momento trágico de perda, o de número 222, 
constitui uma narrativa que gira em torno do nascimento de uma criança. O tom é de júbilo pela chegada do filho, ainda que em condições precárias. Assim, o trecho conclusivo, ao contrário dos trechos anteriores em que o fragmento de duas linhas ilumina o texto posterior. Nesse caso, a narrativa antecede o comentário.

Assim como o tema difere dos exemplos anteriores, a relação entre as personagens também retrata um momento de satisfação pela vida que desabrocha. Enquanto a sequência 33 a 36 explicita o conflito na relação pai-filho num momento de separação irreversível, este último trecho trata da vida que irrompe na vida de um casal. O ambiente grotesco, reduzido ao essencial, indica a privação de recursos: a cena é apresentada em sua crueza, pois o marido faz o parto e para cortar o cordão umbilical ali mesmo, recorre a uma tesoura afiada, cuja lâmina é esterilizada em chama de vela. O sangue que se espalha é lavado pelo marido que a seguir vai fazer o café para ambos, como se fosse um ato de comemoração. O tom é de esperança em relação ao futuro. Contudo, as condições sociais precárias sinalizam as dificuldades futuras a serem enfrentadas pelo ser que nasce nesse ambiente. Os dados exteriores são apresentados à medida que os atos são executados e a alegria que a chegada da criança provoca minimiza o drama existencial dos pais. O discurso direto, entre aspas, verbalizado pelo pai, revela o júbilo como compensação a despeito da miséria rotineira: "Um filho", todo risonho, "é a alegria da casa".

Em oposição à cena do juízo final dos primeiros fragmentos, encontramos aqui um cenário que, apesar da sua precariedade, aponta para a reprodução do drama existencial das personagens relatado anteriormente. Se os primeiros trechos analisados expõem o conflito já estabelecido na relação entre o filho adulto e seu pai, neste trecho ocorre o movimento inverso. Parece que o nascimento da criança em meio ao entusiasmo dos pais já aponta para a repetição dos conflitos existenciais que se projetam no futuro, como os fragmentos 34 e 36 expõem. O último recorte selecionado 223 parece concluir esse raciocínio: "Em busca da palavra certa? Fácil, meu chapa. Siga o fio furtivo da pulga que costura o pêlo negro do cachorro." (sic) (p.118)

O comentário obscuro parece negar qualquer resposta de solução aos fatos existenciais relatados, morte/vida representam um movimento contínuo dos conflitos que se repetem no ambiente social retratado. A vida e a morte representam momentos 
dramáticos de dor e de alegria, o passado e o presente como possibilidade de reprodução do mesmo drama das relações humanas em condições de privação de recursos. Tal perspectiva pode ser percebida por um dos fragmentos derradeiros de número 233: "O conto não tem mais fim que novo começo." (p.123) É, portanto, o drama da repetição, novos personagens surgem para vivenciar os mesmos conflitos afetivos e existenciais que ao longo do tempo se repetem em situações diferenciadas, mas no contexto semelhante. O tom contido expresso numa linguagem crua para relatar os atos e o comportamento das personagens afasta a banalidade sentimental e emotiva.

A estruturação dessas narrativas extremamente condensadas promove a mistura das vozes de personagens em conflito que expressam seus infortúnios pessoais e familiares. Relatam o drama de seus semelhantes com os quais dividem o mesmo ambiente. A representação dessas vozes às vezes ocorre no discurso indireto, às vezes direto e até mesmo pelo indireto livre, tornando ainda mais intensa as relações conflitantes, pois fica a critério do leitor a sua interpretação, obrigando-o a compor a narrativa com o autor, num movimento interativo essencial.

Como não há a descrição do ambiente de modo a caracterizar as personagens, as informações referentes a eles são indiretamente apresentadas nos diálogos e nas cenas relatadas. Pelos elementos referidos de modo secundário na composição da narrativa, assim como o comportamento agressivo que permeia os diálogos, é possível inferir o espaço social em que tais conflitos ocorrem. Como o próprio autor pontua, o cenário de seus contos é o das ruas e dos contextos marginalizados da sociedade. É dele que emergem os diálogos secos e significativos da violência dos sentimentos humanos acirrados pelas condições sociais.

Como o autor evita a sua voz, ela se manifesta de modo sutil, na expressão crua dessas vozes, mas os adjetivos e as imagens sinalizam o tom que mobiliza os embates de modo a provocar o leitor. A simulação das epígrafes que parecem provérbios ou ditos alheios sintetizam um comentário metafórico a respeito dos fatos apresentados. É uma voz impessoal que se manifesta. Como afirma Bakhtin: "... Inserida no contexto do discurso, a palavra do outro não entra em contato mecânico com o discurso que o moldura, mas numa unificação química (no plano semântico e expressivo); segundo ele, 
o grau de influência dialogante recíproca pode ser imenso." (BAKHTIN, 2016, p.133), De acordo com Volóchinov (2017, p.205):

[...] o mundo interior e o pensamento de todo indivíduo possuem seu auditório social estável, e nesse ambiente se formam os seus argumentos interiores, motivos interiores, avaliações etc. Quanto mais culto for um indivíduo, tanto mais o seu auditório se aproximará do auditório médio da criação ideológica, mas, em todo caso, o interlocutor ideal não é capaz de ultrapassar os limites de uma determinada classe e época (VOLOCHÍNOV, 2017, p.205).

O comportamento e os diálogos dessas personagens expressam suas concepções e sentimentos decorrentes dos relacionamentos com familiares pessoas em condições semelhantes. Os fragmentos expõem os embates vivenciados que propiciam o assomo da natureza mais primitiva do ser humano. Os laços afetivos são mesclados pelas necessidades imediatas que atuam sobre o desejo, o amor e as relações sociais. Portanto, a proposta valorativa do autor manifesta-se na seleção dos recursos expressivos: imagens, diálogos e a estruturação sintática. Trevisan expressa desse modo sua percepção do ser humano afetado pela privação, pela falta de condições e pela premência de sua natureza mais primitiva. Os sentimentos emergem sem retoques e os embates conflitivos atingem o clímax: nascimento, morte, amor e ódio se alternam nesses fragmentos compondo um cenário trágico do ser humano.

Trevisan não inicia nem finaliza suas ministórias. Fica a critério do leitor preencher a falta dessas informações que podem ser indiretamente sinalizadas na sequência das cenas em forma de clips.

O autor confia na capacidade interpretativa de seu público ainda que desconheça de modo profundo as condições existenciais desses seres marginalizados, cujo drama se desenrola de modo violento na intimidade familiar.

O estilo do autor permite a intervenção do leitor e em consequência dos recursos linguísticos que organizam os fragmentos. Assim propicia a discussão de questões linguísticas que podem mobilizar a intervenção dos leitores(alunos), propiciando atividades de interação com o texto ficcional.

Pelas análises, é possível sugerir questões a respeito da organização estrutural da linguagem, destacando a ausência de elementos de coesão, assim como a ausência de 
linearidade narrativa, própria dos enunciados que obedecem à sequência lógica dos fatos narrados.

A estruturação desses minicontos dispensa a lógica gramatical exigindo do leitor uma resposta interativa para o suprimento das lacunas deixadas pelo relato. Esse é o desafio proposto por Trevisan e que pode sugerir uma discussão produtiva a respeito de tópicos gramaticais, tais como o emprego de termos de coesão, as formas de inserção dos diálogos na narrativa como resultado de propostas enunciativas diferenciadas em relação ao horizonte social do público a que se destina.

Dessa forma, reconstruir trechos dos diversos fragmentos, reestruturando-os de acordo com a norma, possibilita a comparação dos efeitos de sentido produzidos em função de propostas comunicativas diferenciadas. Portanto, o conceito de gênero discursivo é fundamental para a discussão da linguagem e da produção dos enunciados, tornando o ensino da gramática mais dinâmico e talvez mais eficaz, ao mobilizar os alunos de modo interativo.

Os fragmentos narrativos ainda podem suscitar outros tópicos para discussão dependendo do nível de aprendizagem dos alunos e das necessidades que apresentam. Esse é o desafio que o professor enfrenta pondo em prática sua criatividade de forma interativa com os alunos.

\section{Conclusão}

A teoria bakhtiniana torna-se produtiva para o desenvolvimento de ações mais eficazes no ensino de língua. Nessa concepção discursiva de linguagem, o conhecimento linguístico torna-se mais dinâmico em consonância com a natureza viva da língua, conforme propõe Bakhtin. Sob esse aspecto, o conceito de gênero discursivo é fundamental para a análise da linguagem em suas manifestações concretas: a proposta enunciativa, o tema, a forma composicional e o estilo revelador das relações entre o indivíduo e o contexto de produção, ou seja, seu público presumido. O estilo do enunciado é indicador de atitudes responsivas do autor desvelando seus valores éticos/estéticos diante dos conflitos sociais de que participa. 
A exemplo dos minicontos, outros gêneros podem ser discutidos tendo em vista a concepção dialógica da linguagem. Tal concepção considera as relações entre enunciador e público, assim como o tema e a proposta comunicativa do autor como elementos essenciais na composição dos enunciados. Essa é a questão relevante apontada pelo Bakhtin professor em sua experiência de ensino, na década de 40 na Rússia, como explicita em Questões de estilística no ensino de língua (2013). Nessa vertente não há regras absolutas, assim como não há soluções prontas. O exercício didático é sempre resultado das relações professor/aluno e das necessidades específicas de cada grupo e de seus conhecimentos prévios.

\section{Referências}

BAKHTIN. M.M. Os gêneros do discurso, (Trad. do russo, organização, notas e posfácio de Paulo Bezerra, notas da ed. russa Serguei Botcharov). São Paulo: Editora 34, 2016

M. M. Teoria do romance I: a estilística. (Tradução da edição russa organizada por S. Botcharov e V. Kójinov; prefácio, notas e glossário Paulo Bezerra). São Paulo: Editora 34, 2015.

Questões de estilística no ensino da língua (Trad. Sheila Grillo e Ekaterina Vólkova Américo) 1 1a ed. São Paulo: Editora 34, 2013.

BUNZEN, C. MENDONÇA, M. (Orgs) Múltiplas linguagens para o Ensino Médio. São Paulo: Parábola Editorial, 2013.

KLEIMAN et al. Projetos de letramento no ensino médio. In BUNZEN, C. MENDONÇA, M.(Orgs) Múltiplas linguagens para o Ensino Médio. São Paulo: Parábola Editorial, 2013, p. 69-83.

PUZZO, M. O discurso do outro na reportagem de Eliane Brum. In Caminhos em linguística aplicada, V.21, n² 2, 2019, p.178-198.

. Sintaxe, pontuação e estilo no conto As margens da alegria de G. Rosa. In KOZMA, E. V. B.; PUZZO, M.B.; UYENO, E.Y. (Orgs) Os sinais de pontuação e seus efeitos de sentido: uma abordagem discursiva. V. 39, Campinas, SP: Pontes Editores, 2014, p.193-218.

Journalistic narrative: a story of real life. In CABECINHA, R.; ABADIA, L. (Orgs)Theoretical and Methodological Approaches. Minho/ Portugal: Universidade do Minho, 2013, p.134-144. 
A pontuação no texto literário e a constituição de sentido. In UYENO, E. Y.; PUZZO, M. B.; RENDA, V. L. S. (Orgs) Linguística Aplicada, Linguística e Literatura: Intersecções Profícuas. Campinas, SP: Pontes Editores, 2012, p.71-93.

TREVISAN, D. 234: ministórias. Rio de janeiro/São Paulo: Editora Record, 1997.

ROJO, R. (Org.) Escola conectad@: os multiletramentos e as TICs.1 a ed. São Paulo: Parábola Editorial, 2013.

MOURA, E. (Orgs) Multiletramentos na escola. São Paulo: Parábola Editorial, 2012.

BARBOSA, J. Hipermodernidade, multiletramentos e gêneros discursivos. $1^{\mathrm{a}}$ ed. São Paulo: Parábola Editorial, 2015.

VOLÓCHINOV, V. N. Marxismo e filosofia da linguagem. (Tradução, notas e glossário, Sheila Grillo e Ekaterina V. Américo); (Ensaio introdutório, Sheila Grillo) São Paulo: Editora 34, 2017.

A palavra na vida e a palavra na poesia: introdução ao problema da poética sociológica. In A construção da enunciação e outros ensaios. (Trad. João Wanderley Geraldi) São Carlos: Pedro \& João, 2013 a, p. 71-100

A construção da enunciação. In $A$ construção da enunciação e outros ensaios. (Trad. João Wanderley Geraldi) São Carlos: Pedro \& João, 2013 b, p. 157-188.

i Professora aposentada da Universidade de Taubaté, membro do Programa de Mestrado em Linguística Aplicada.

puzzo@uol.com.br

\section{RECEBIDO EM 05/07/2019 \\ ACEITO EM 27/09/2019}

